\title{
Increased maximum gradient amplitude improves robustness of spin-echo cardiac diffusion- weighted MRI
}

\author{
Eric Aliotta ${ }^{1,2^{*}}$, Stanislas Rapacchi ${ }^{1}$, Peng Hu ${ }^{1,2}$, Daniel B Ennis ${ }^{1,2}$ \\ From 18th Annual SCMR Scientific Sessions \\ Nice, France. 4-7 February 2015
}

\section{Background}

Cardiac motion presents a major challenge in diffusion weighted MRI (DWI), often leading to large signal dropouts that necessitate repeated measurements (Pai, V.M., MRM 2011). While cardiac DWI is generally ECG gated to apply diffusion weighting during peak-systole or enddiastole, these intervals can be short and difficult to pinpoint, resulting in poor sequence reproducibility.

Recent improvements in gradient hardware provide larger maximum gradients than current systems $\left(G_{\max }=80 \mathrm{mT} / \mathrm{m}\right)$, which can substantially reduce the temporal footprint of diffusion preparation and make cardiac DWI more robust to bulk motion.

\section{Methods}

A left ventricular (LV) motion model simulated motion of the healthy heart with $30-70 \mathrm{~ms}$ quiescent intervals $\left(t_{\mathrm{Q}}\right)$. Monopolar encoded SE-DWI $\left(b=500 \mathrm{~s} / \mathrm{mm}^{2}, 3\right.$ directions) was simulated using: $G_{\max }=40$ and $80 \mathrm{mT} / \mathrm{m}$ with diffusion gradients centered at mid-quiescence and with a range temporal offsets $(\Delta \mathrm{T}= \pm 20 \mathrm{~ms})$. Complex Gaussian noise was added such that $S N R=50$ for $b=0$ images. Bulk motion induced error was measured by the bias in apparent diffusion coefficient (ADC) recovery from the programmed value $\left(A D C=1 \times 10^{-3} \mathrm{~mm}^{2} / \mathrm{s}\right)$. Sequences that recovered $\mathrm{ADC}$ with bias $<10 \%$ for $\Delta \mathrm{T}=$ $\pm 10 \mathrm{~ms}$ were deemed robust to motion.

Three healthy volunteers were scanned in a $3.0 \mathrm{~T}$ Siemens Prisma $(G \max =80 \mathrm{mT} / \mathrm{m})$ scanner using breath hold cardiac DWI (12 directions, monopolar encoding, single-shot SE EPI readout). Five repetitions of each sequence were acquired: 1) G40-b300: $\mathrm{G}_{\max }=40 \mathrm{mT} / \mathrm{m}$, $\mathrm{b}=300 \mathrm{~mm}^{2} / \mathrm{s}$, TE $\left.=44 \mathrm{~ms} ; 2\right)$ G40-b100: $\mathrm{G}_{\max }=40 \mathrm{mT} / \mathrm{m}$, $\mathrm{b}=100 \mathrm{~mm}^{2} / \mathrm{s}, \mathrm{TE}=36 \mathrm{~ms}$; and 3) G80-b300: $\mathrm{G}_{\max }=80 \mathrm{mT} /$ $\mathrm{m}, \mathrm{b}=300 \mathrm{~mm}^{2} / \mathrm{s}, \mathrm{TE}=36 \mathrm{~ms}$. Imaging was timed to the diastolic quiescent interval, which was determined visually from CINE images.

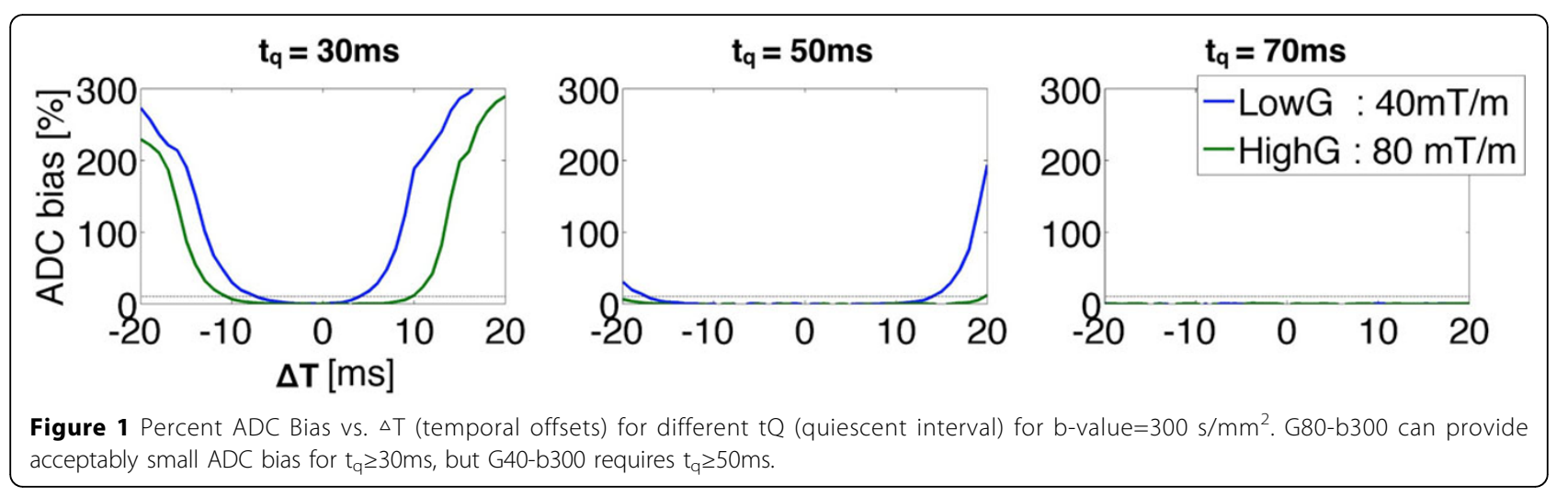

Radiology, UCLA, Los Angeles, CA, USA

Full list of author information is available at the end of the article

(0) 2015 Aliotta et al; licensee BioMed Central Ltd. This is an Open Access article distributed under the terms of the Creative Commons 


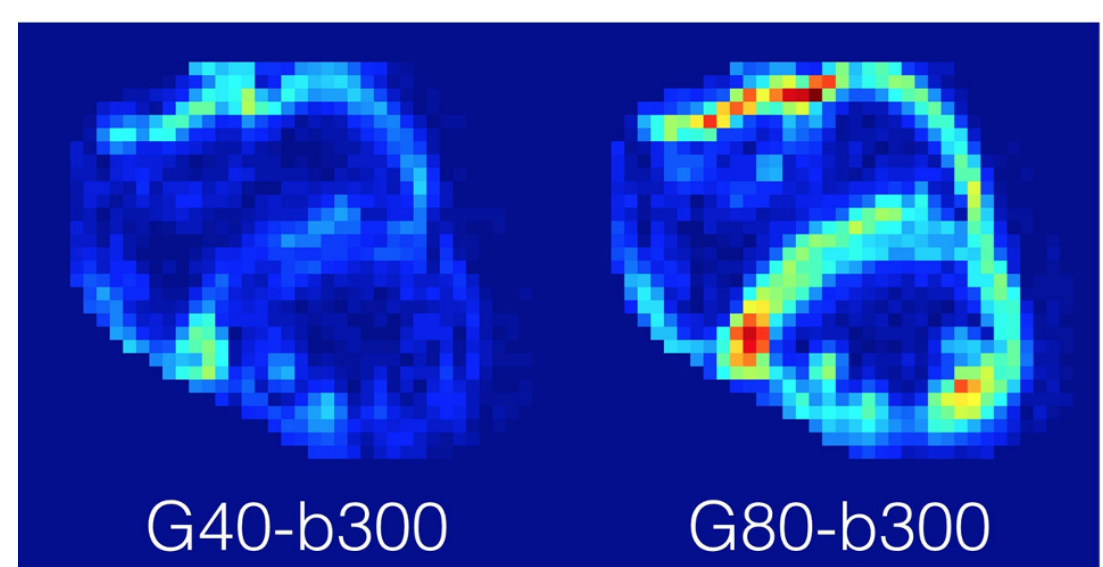

Figure 2 Typical DWI from G40-b300 (left) and G80-b300 (right). Image quality was generally better for G80-b300.

Two observers evaluated the quality of all images as: "acceptable"-no significant signal dropouts in myocardium or "unacceptable"-significant signal dropouts, and directly compared G40-b300 to G80-b300 (fixed bvalue).

\section{Results}

The simulated ADC bias (Fig. 1) shows that G80-b300 can provide acceptably small ADC bias for $t_{q} \geq 30 \mathrm{~ms}$, but G40-b300 requires $t_{q} \geq 50 \mathrm{~ms}$.

Image quality was better in G80-b300 than G40-b300 in $86 \%$ of images (example pair shown in Figure 2). 55\% of G80-b300 images were acceptable, whereas $30 \%$ of G40-b300 and 70\% of G40-b100 were.

\section{Conclusions}

Simulations show that G80 recovered ADC more accurately than $\mathrm{G} 40$ for all $\mathrm{t}_{\mathrm{Q}}$ and $\Delta \mathrm{T}$ and was robust to motion for $t_{Q} \geq 30 \mathrm{~ms}$. This is likely due to the shorter diffusion preparation ( $G 40 \mathrm{t}_{\text {prep }}=39 \mathrm{~ms}$, G80 $\mathrm{t}_{\text {prep }}=28 \mathrm{~ms}$ ) and indicates that G80 will perform more consistently for short $t_{\mathrm{Q}}$ (fast heart rates, systolic imaging) or changes in heart rhythm.

With fixed b-value $=300 \mathrm{~mm}^{2} / \mathrm{s}$ in vivo, G80 had consistently better image quality than G40. In agreement with simulation, this indicates that G80 improves the robustness of cardiac DWI for the same b-value. With fixed TE $=36 \mathrm{~ms}$, G40-b100 was acceptable more frequently than G80-b300, but with insufficient diffusion weighting. Increased $G_{\max }$ can thus improve diffusion sensitivity with less loss of robustness.

\section{Funding}

This research was supported by Siemens Medical Solutions and the Department of Radiological Sciences at UCLA.
Authors' details

${ }^{1}$ Radiology, UCLA, Los Angeles, CA, USA. ${ }^{2}$ Biomedical Physics IDP, UCLA, Los Angeles, CA, USA.

Published: 3 February 2015

doi:10.1186/1532-429X-17-S1-P388

Cite this article as: Aliotta et al:: Increased maximum gradient

amplitude improves robustness of spin-echo cardiac diffusion-weighted MRI. Journal of Cardiovascular Magnetic Resonance 2015 17(Suppl 1):P388.

Submit your next manuscript to BioMed Central and take full advantage of:

- Convenient online submission

- Thorough peer review

- No space constraints or color figure charges

- Immediate publication on acceptance

- Inclusion in PubMed, CAS, Scopus and Google Scholar

- Research which is freely available for redistribution 